\title{
A case report of recurrent $\mathrm{C} 3$ glomerulonephritis 18 months after renal transplantation
}

\author{
Hiroko Kakita', Takafumi Miyake ${ }^{3}$, Toshiyuki Komiya ${ }^{2}$, Tatsuo Tsukamoto $^{3}$ and Eri Muso ${ }^{1 *}$
}

\begin{abstract}
Background: The recurrence of glomerulonephritis $(G N)$ is critical to the prognosis of long-term renal transplant graft survival. C3 GN is a rare GN with a poor prognosis, and there are only a few reports of recurrent cases after renal transplantation. We recently experienced a case highly suspected of C3 GN recurrence.
\end{abstract}

Case presentation: The patient was a 67-year-old male who had suffered from end-stage renal disease (ESRD) and started dialysis at the age of 60 . His primary renal disease was unknown. At the age of 63, renal transplantation was successfully performed. His serum creatinine $(\mathrm{Cr})$ level was maintained at 1.2 to 1. $5 \mathrm{mg} / \mathrm{dl}$, with no urinary protein or occult blood until 18 months after the transplant when urinary occult blood and protein became constant, along with an elevated $\mathrm{Cr}$ level at 1.5 to $1.6 \mathrm{mg} / \mathrm{dl}$. The tentative diagnosis following a protocol biopsy at 36 months was dense-deposit disease. However, the pathological findings of an episode biopsy performed 1 year later, when his $\mathrm{Cr}$ level elevated to $2.0 \mathrm{mg} / \mathrm{dl}$ after varicella zoster virus reactivation, revealed no acute rejection but were compatible with C3 GN.

Conclusions: These findings are consistent with a previous report on recurrent C3 GN that revealed relatively rapid loss of graft function, contrasting well with slow progression occurring in the native kidney. This case is possibly the first report in Japan of recurrent C3 GN after renal transplantation.

\section{Background}

The recurrence of glomerulonephritis (GN) is a critical risk factor for long-term renal transplant graft survival. C3 GN is a rare GN with poor prognosis, and there are only a few reports of recurrent cases after renal transplantation. The following report details a case highly suspected of C3 GN that we recently experienced.

\section{Case presentation}

A 67-year-old male suffering from end-stage renal disease (ESRD) underwent successful renal transplantation (from a donation after cardiac death) at the age of 63. The serum Cr level was maintained at 1.2 to $1.5 \mathrm{mg} / \mathrm{dl}$, and proteinuria and hematuria were negative. The most recent

\footnotetext{
* Correspondence: muso@kitano-hp.or.jp

'Department of Nephrology and Dialysis, Tazuke Kofukai Medical Research Institute, Kitano Hospital, 2-4-20 Ohgimachi, Kita-ku, Osaka 530-8480, Japan

Full list of author information is available at the end of the article
}

immunosuppression regimen was prednisolone (PSL), mycophenolate mofetil (MMF), and tacrolimus (TAC) (Fig. 1). As the causative disease of renal death, chronic GN, such as IgA nephropathy, was suspected from clinical manifestations such as a past history of macrohematuria after an influenza virus infection at the age of 30 and sustained microhematuria with proteinuria. The patient's renal function gradually declined to a $\mathrm{Cr}$ level of $2.5 \mathrm{mg} / \mathrm{dl}$ at the age of 56. At the age of 59, after malignant hypertension possibly due to the stress of hard work, along with an accompanying upper respiratory infection, there was a rapid decline in renal function leading to ESRD at the age of 60, and dialysis was started. A sustained low C3 level of $30 \mathrm{mg} /$ $\mathrm{dl}$ from the age of 59 at the first visit to our hospital suggested the possibility of $\mathrm{C} 3$ glomerulopathy (C3GP), although neither the $\mathrm{C} 3$ nephritic factor, factor $\mathrm{H}$ antibody, nor the complement factor $\mathrm{H}(\mathrm{CFH})$, complement factor I (CHI), and complement factor H-related 1-5 (CFHR1-5) genes were checked. A 1-h protocol biopsy after 


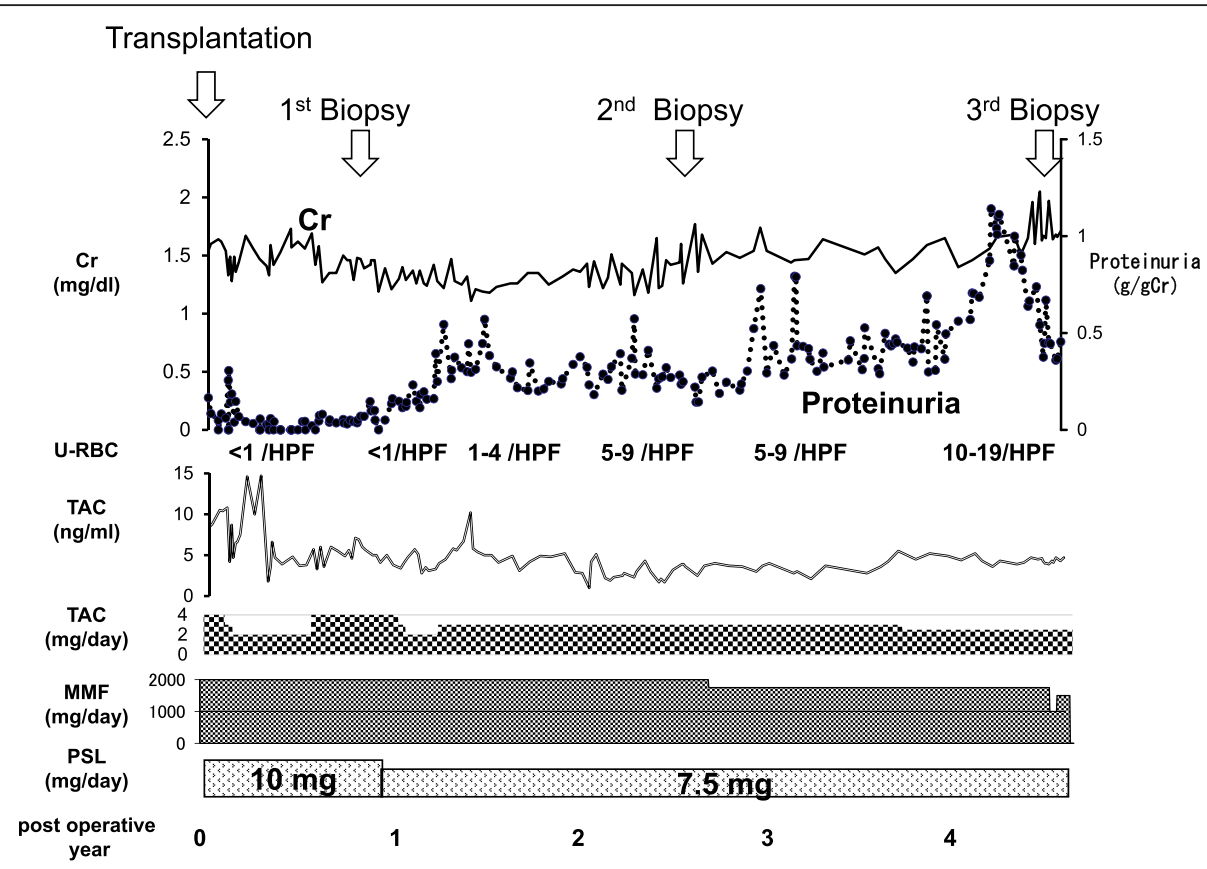

Fig. 1 The serum levels of creatinine (Cr) and proteinuria after renal transplantation. The dosages of mycophenolate mofetil (MMF), prednisolone (PSL), and tacrolimus (TAC) are indicated by bars. Trough blood concentration of tacrolimus (TAC) is indicated by a line graph. After transplantation, his serum Cr level was maintained at 1.2 to $1.5 \mathrm{mg} / \mathrm{dl}$ and proteinuria and hematuria were negative. The first protocol biopsy was performed 1 year after the transplant when his serum Cr level was maintained at 1.3 to $1.4 \mathrm{mg} / \mathrm{dl}$ and neither proteinuria nor hematuria was detected. From the second year after transplantation, transient hematuria and proteinuria started to be detected, and at POY 1.6, urinary abnormality became constant. When the second protocol biopsy was performed at POY 3, his serum Cr was maintained at 1.3 to $1.4 \mathrm{mg} / \mathrm{dl}$, but proteinuria around $150 \mathrm{mg} / \mathrm{gCr}$ and hematuria $1+$ with dysmorphic red blood cells were observed. His serum $\mathrm{Cr}$ increased gradually to around 1.5 to $1.6 \mathrm{mg} / \mathrm{dl}$, and when an episode biopsy was performed after a herpes zoster virus infection in post-operative year 4, the serum Cr had elevated rapidly to $2.0 \mathrm{mg} / \mathrm{dl}$. Proteinuria was around $400 \mathrm{mg} / \mathrm{gCr}$ and hematuria was 3+
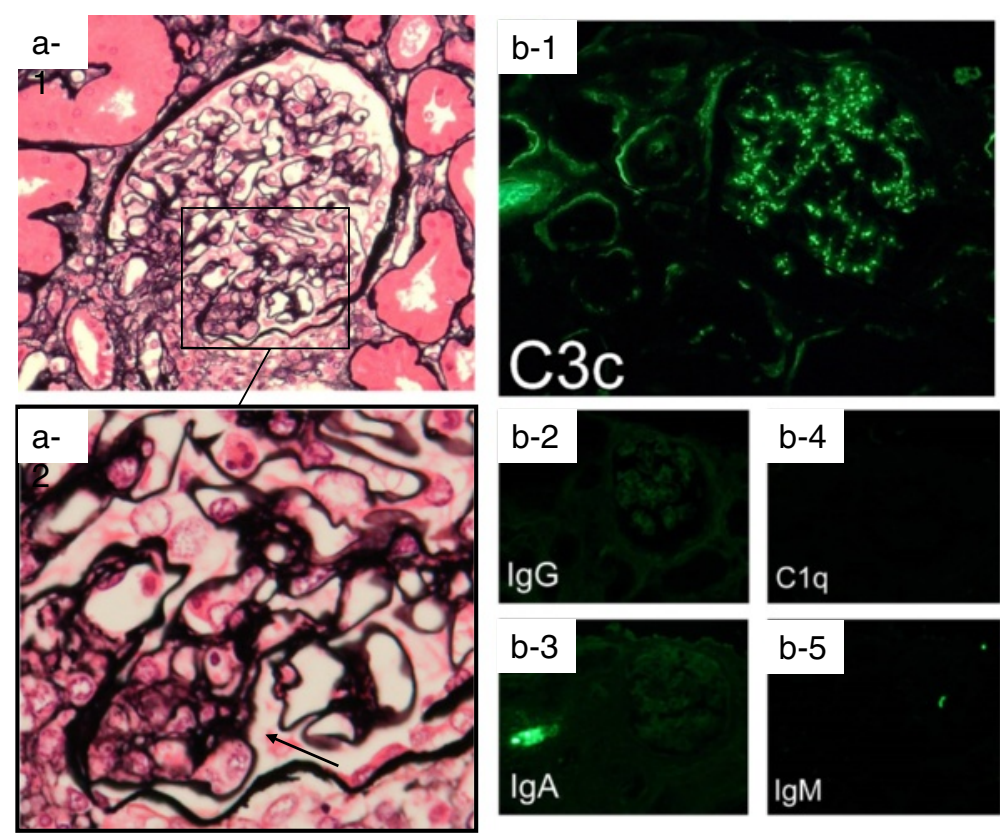

Fig. 2 Pathological findings of the first protocol biopsy (first biopsy). a-1 Light microscopy findings. Glomerulus showed very mild mesangial matrix expansion and segmental proliferation at the vascular pole (Original magnification, $\times 200$ ). $\mathbf{a}-\mathbf{2}$ High magnification of black-boxed area in a-1. The arrow shows segmental proliferation (original magnification, $\times 400$ ). b Glomerular immunofluorescent staining (original magnification, ×100). b-1 Global mesangial granular deposits of C3c. b-2 No apparent lgG deposition was observed. b-3 No apparent IgA deposition was observed. b-4 No apparent lgM deposition was observed. b-5 No apparent C1q deposition was observed 
transplantation revealed a 2 out of 23 glomerular global sclerosis level, a normal mesangial matrix and cellularity with patent capillary lumens having a normal capillary wall thickness. Additionally, although there was no abnormality of the small arteries or arterioles, mild interstitial fibrosis with very segmental tubular atrophy was observed on light microscopy (LM). Immunofluorescence staining (IF) and electron microscopic (EM) evaluation were not performed.

As shown in Fig. 1, the first protocol biopsy was performed 1 year after the transplant (post-operative year 1 (POY 1)) when his serum $\mathrm{Cr}$ level was maintained at 1.3 to $1.4 \mathrm{mg} / \mathrm{dl}$ and neither proteinuria nor hematuria was detected. LM findings were compatible with the initial stage of membranoproliferative glomerulonephritis (MPGN). The glomerulus showed very mild mesangial matrix expansion and segmental proliferation at the vascular pole (Fig. 2a). IF showed positive, but not severe, global mesangial granular C3c (1+) deposits with no apparent immunoglobulin (Ig) deposition (Fig. 2b). No evidence of rejection was found, and recurrent GN was suspected. From the second year after transplantation, transient hematuria and proteinuria were detected, and at POY 1.6, urinary abnormality became constant at the age of 65 . When the second protocol biopsy was performed at POY 3 , his serum $\mathrm{Cr}$ was maintained at 1.3 to $1.4 \mathrm{mg} / \mathrm{dl}$, but proteinuria around $150 \mathrm{mg} / \mathrm{gCr}$ and hematuria $1+$ with dysmorphic RBC

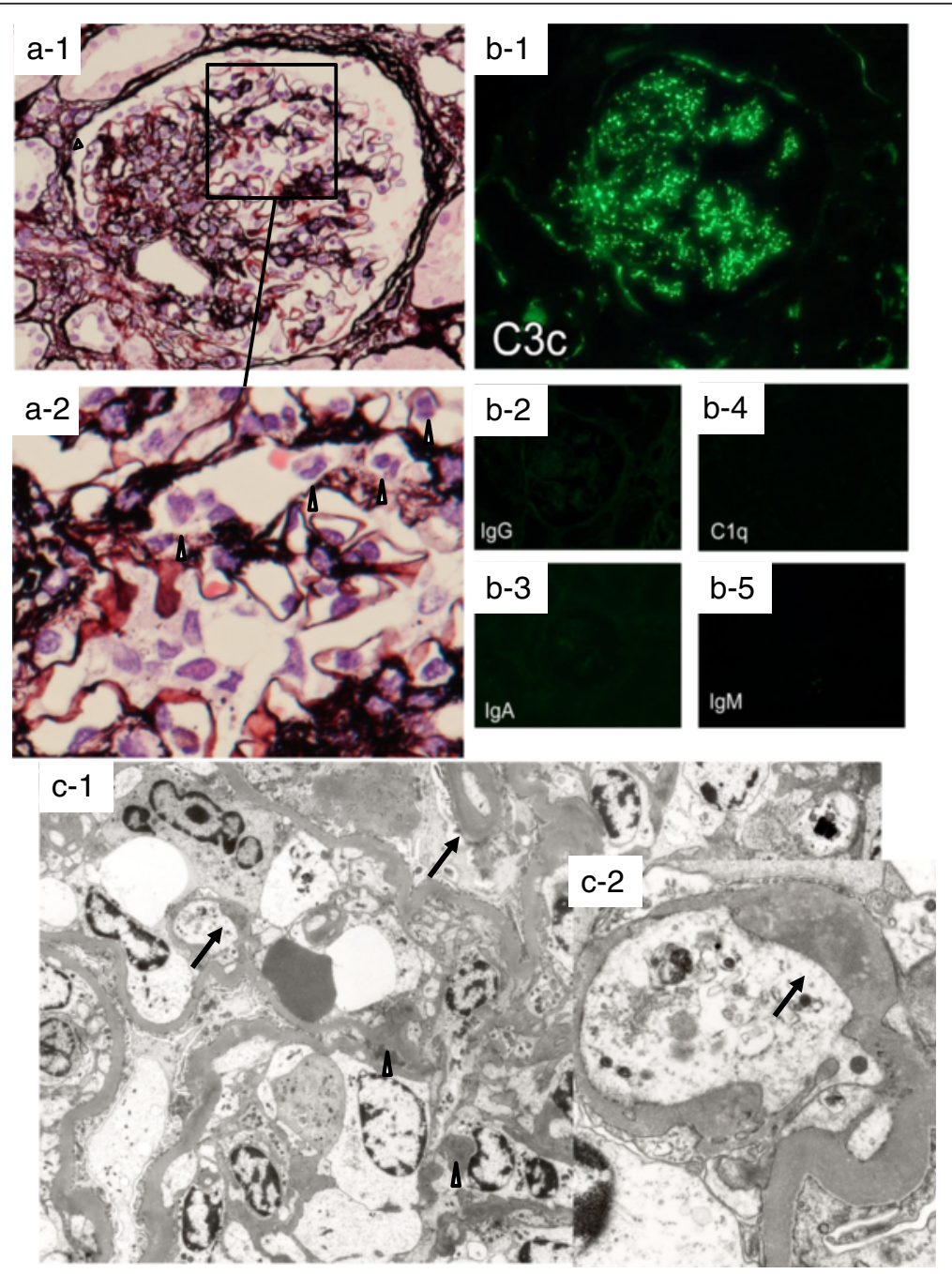

Fig. 3 Pathological findings of the second protocol biopsy (second biopsy). a-1 Glomerulus showed mild mesangial matrix expansion and segmental proliferation at the vascular pole. a-2 High magnification of the black-boxed area in a-1 (original magnification, $\times 400$ ). Inflammatory cells were observed in capillary lumens (arrowhead). b Glomerular immunofluorescent staining (original magnification, ×100). b-1 Global mesangial and capillary granular deposits of C3c. b-2 No apparent lgG deposition was observed. b-3 No apparent lgA deposition was observed. b-4 No apparent IgM deposition was observed. b-5 No apparent C1q deposition was observed. c-1 Dense deposits were observed within the glomerular basement membrane (arrow) and in the mesangium (arrowhead) on electron microscopy (original magnification, $\times 3000$ ). $\mathbf{c}-\mathbf{2}$ Dense deposits were observed within the glomerular basement membrane (arrow) on electron microscopy (original magnification, $\times 8000$ ) 
were observed (Fig. 1). The LM finding was compatible with focal segmental MPGN with focal arteriolopathy (Fig. 3a). IF showed severe (3+) C3 granular deposition at the mesangium and along the capillary wall without any apparent Ig deposition (Fig. 3b). EM showed global mesangial proliferation and matrix expansion with an electron-dense deposit at the mesangium and along the basement membrane (Fig. 3c). From these findings, the re-starting stage of dense-deposit disease with arteriolar hyalinosis grade 2 was diagnosed. His serum $\mathrm{Cr}$ increased gradually to around 1.5 to $1.6 \mathrm{mg} / \mathrm{dl}$, and when an episode biopsy was performed after a varicella zoster virus (VZV) infection at POY 4, the serum $\mathrm{Cr}$ had elevated rapidly to $2.0 \mathrm{mg} / \mathrm{dl}$ (Fig. 1). Proteinuria was around $400 \mathrm{mg} / \mathrm{gCr}$, and hematuria was $3+$. The LM finding revealed typical MPGN (Fig. 4a), and arteriolar hyalinosis had also progressed to grade 3 with interstitial fibrosis at less than $25 \%$. IF showed more global and more severe fine granular, but not a dense-deposit disease-like, deposition of $\mathrm{C} 3$ at the mesangium and along the capillary wall which was negative for Ig deposition (Fig. 4b). EM also showed global mesangial proliferation and matrix expansion with fine electron-dense deposits at the mesangium and subendothelial areas, but no dense-deposit disease-like deposition in the glomerular basement membrane (Fig. 4c). These findings were compatible with C3 GN. After recovery from the VZV infection, his $\mathrm{Cr}$ level returned to the baseline
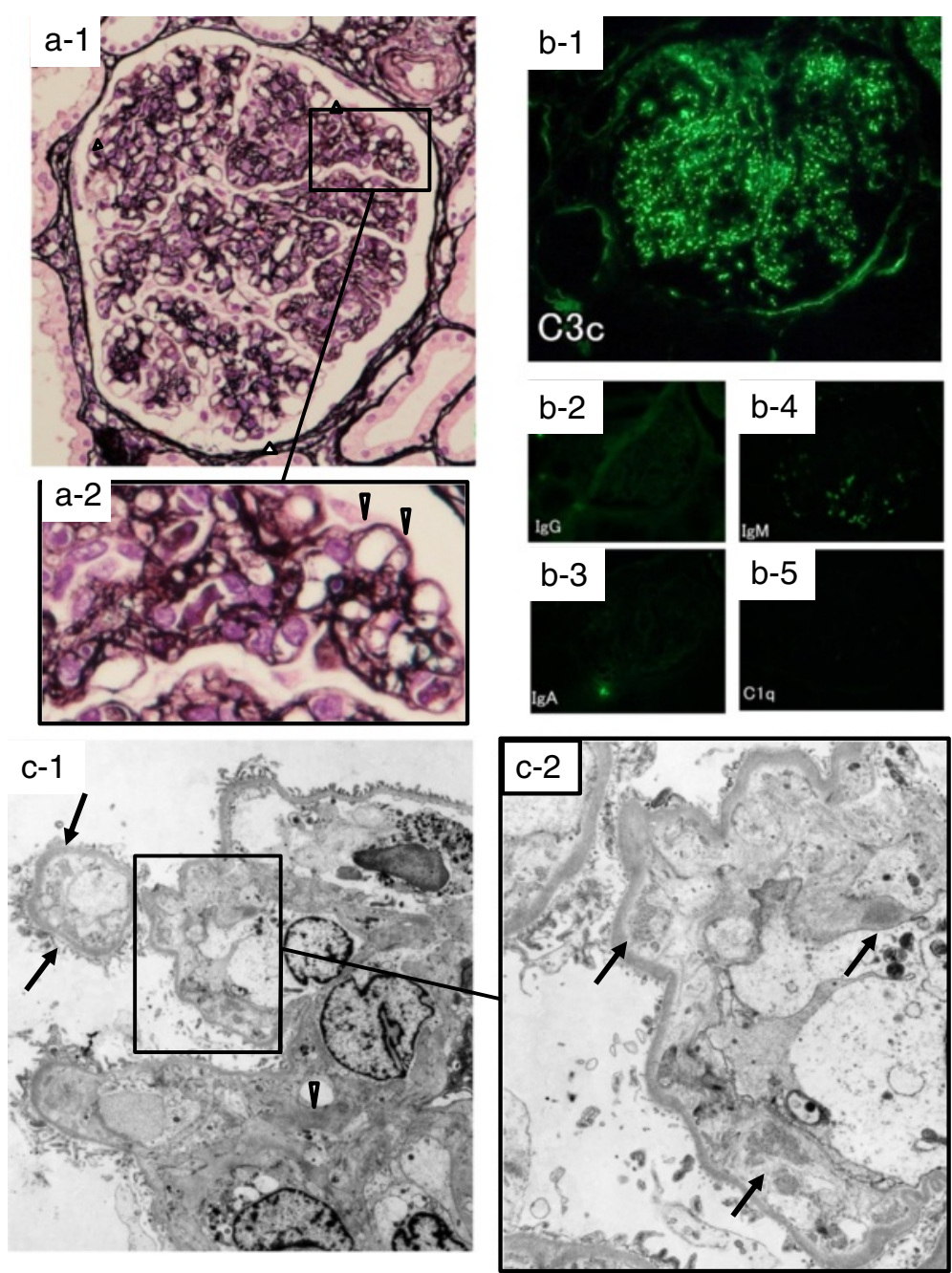

Fig. 4 Pathological findings of the episode biopsy (third biopsy). a-1 Glomerulus showed hyper-cellularity and mesangial interposition was observed. a-2 High magnification of black-boxed area in $\mathbf{a}-\mathbf{1}$. The arrow shows duplication of the glomerular basement membrane. $\mathbf{b}$ Glomerular immunofluorescent staining (original magnification, $\times 100$ ). b-1 Global mesangial and capillary granular deposits of C3c. b-2 No apparent lgG deposition. b-3 No apparent lgA deposition. b-4 Segmental lgM deposition. b-5 No apparent C1q deposition. c-1 Subendothelial deposits (arrow) were observed on electron microscopy (original magnification, $\times 3000$ ). c-2 Subendothelial deposits (arrow) were observed on electron microscopy (original magnification, $\times 8000$ ) 
temporarily; however, renal function deterioration progressed and serum $\mathrm{Cr}$ rose to $2.0 \mathrm{mg} / \mathrm{dl}$ at 1 year after the third biopsy.

\section{Discussion}

C3 glomerulopathy (C3GP) is a rare disease that is due to abnormalities in the alternative pathway (AP) suspected of being caused either by autoantibodies or genetic abnormalities in the AP pathway. C3GP includes dense-deposit disease (DDD) and C3 GN, both of which show glomerular deposition only for C3, but an absence of Ig deposition on IF. Sethi et al. reported EM findings with mesangial and/or subendothelial, intramembranous, and subepithelial depositions in C3 GN. The depositions were amorphous and appeared lighter and less sharply demarcated than immune-type electron-dense deposits [1]. In our case, there was $\mathrm{C} 3$ staining at the mesangium and capillary and a lack of $\mathrm{C} 1 \mathrm{q}, \mathrm{C} 4 \mathrm{c}$, and Ig depositions on IF. An amorphous deposition was observed at the subendothelial and mesangial areas on EM at the third biopsy. Using these findings, we diagnosed C3 GN. Although C3 deposition was observed from the first biopsy, without any history of apparent infection, infection-related GN was incompatible.

The recurrence of C3GP after renal transplantation is relatively common (Table 1). Some of these cases showed early recurrence and rapid loss of graft function consistent with our case. However, the graft prognosis was not always poor in other cases. In our case at the age of 30, hematuria was firstly noted after influenza virus infection, which suggested it was a trigger for the C3GP disease expression. In addition, after transplantation, for patients with a background of this disease with a persistent low complement, any inflammatory event requiring complement activation could provoke or aggravate a related disease such as C3GP. Ischemia-reperfusion injury due to transplantation activates the complement cascade, and $\mathrm{C} 3$ production is upregulated first in the mesangial cells and vessels and 2 days later in tubular epithelial cells and glomerular parietal cells in the graft kidney [2]. From this viewpoint, the transplant operation itself may have been the trigger for C3GP, and this could explain the early recurrence in the graft kidney of C3GP observed in this patient. Based on his relatively rapid loss of graft function, the VZV infection likely became the second trigger for renal disease aggravation, and the age of both the donor and recipient may have been another factor in addition to the single kidney.

There is no established treatment for C3GP. For complement dysregulation in the pathogenesis of this disease, a supply of normal plasma has been suggested. Recently, a new therapy targeting an alternative complement pathway using the anti-C5 antibody [3-8] and soluble CR1 [9] has been reported. However, controlled trials regarding the efficacy of these treatments have not yet been conducted. Reports on recurrent cases in grafts are very limited. To improve long-term graft survival, further investigation of treatment not only for the native kidney but also for the graft should be done.

\section{Conclusions}

In summary, compared to the native kidney, early recurrence and rapid loss of graft function was observed in our case. To better assess the indication of renal transplantation, further accumulation of such cases is required.

Table 1 Reports of recurrent C3 glomerulopathy after renal transplantation

\begin{tabular}{|c|c|c|c|c|c|c|}
\hline & Diagnosis & Number & ESRD & $\begin{array}{l}\text { Kidney } \\
\text { transplant }\end{array}$ & Recurrence & Prognosis \\
\hline Athanasiou $Y$ et al (2011) [9] & CFHR5 nephropathy & 91 & 18 & 10 & Unknown & $\begin{array}{l}\text { One patient had a second transplant. } \\
\text { Eight patients are well } 1 \text { to } 23 \text { years intact }(\mathrm{Cr} 0.9 \mathrm{mg} / \mathrm{dl}) \text {. }\end{array}$ \\
\hline Servais et al (2007) [10] & $\begin{array}{l}\text { Glomerulonephritis } \\
\text { (GN) with isolated } \\
\text { C3 deposits }\end{array}$ & 19 & 3 & 2 & 1 & $\begin{array}{l}\text { No recurrence at } 2 \text { months after transplantation } \\
(\mathrm{C} 3 \mathrm{NeF}+) \text {. } \\
\text { Recurrence at } 1 \text { month after transplantation with } \\
\text { proteinuria and normal renal function ( } 3 \mathrm{NeF}-\text { ). }\end{array}$ \\
\hline Olivia Boyer et al (2008) [11] & $\begin{array}{l}\text { Atypical hemolytic } \\
\text { and uremic syndrome } \\
\text { associated with CFH } \\
\text { deficiency }\end{array}$ & 2 & 2 & 2 & 2 & $\begin{array}{l}\text { C3 deposition was positive at } 5 \text { years } \\
\text { post-transplantation. } \\
\text { Kidney function is stable } 9 \text { years after transplantation. } \\
\text { Recurrence of GN with isolated C } 3 \text { deposits } 5 \text { months } \\
\text { later after kidney transplantation and TMA } 4 \text { years later. } \\
\text { Six years later, kidney function was stable with regular } \\
\text { plasma therapy. }\end{array}$ \\
\hline Sethi et al (2012) [1] & C3 GN & 12 & 2 & 2 & 2 & $\begin{array}{l}\text { Recurrence of C } 3 \text { GN within } 1 \text { to } 1.5 \text { years of kidney } \\
\text { transplantation. (One was C } 3 \mathrm{NeF} \text { positive, another } \\
\text { was C } 3 \text { risk allele positive.) }\end{array}$ \\
\hline Vernon KA et al (2011) [12] & CFHR5 nephropathy & 1 & 1 & 1 & 1 & $\begin{array}{l}\text { Right after the transplantation, persistent microscopic } \\
\text { hematuria was observed. }\end{array}$ \\
\hline
\end{tabular}

Abbreviations: CFHR5 complement factor H-related 5, GN glomerulonephritis, C3NeF C3 nephritic factor, CFH complement factor $\mathrm{H}, \mathrm{TMA}$ thrombotic microangiopathy, C3 GN C3 glomerulonephritis 


\section{Abbreviations}

AP, alternative pathway; C3GP, C3 glomerulopathy; C3NeF, C3 nephritic factor; $\mathrm{CFH}$, complement factor H; CFHR1-5, complement factor H-related 1-5; $\mathrm{CHI}$, complement factor $\mathrm{I}$; $\mathrm{Cr}$, creatinine; DDD, dense-deposit disease: EM, electron microscopy; ESRD, end-stage renal disease; GN, glomerulonephritis; IF, immunofluorescence; Ig, immunogloblulin; LM, light microscopy; MMF, mycophenolate mofetil; MPGN, membranoproliferative glomerulonephritis; POY, post-operative year; PSL, prednisolone; TAC, tacrolimus; TMA, thrombotic microangiopathy; VZV, varicella zoster virus

\section{Authors' contributions}

$H K, T M, T K, T T, E M$ took care of this patient and participated in decision of treatment. HK prepared the manuscript. EM revised it critically for important intellectual content. All authors read and approved the final manuscript.

\section{Competing interests}

The authors declare that they have no competing interests.

\section{Consent}

Written informed consent was obtained from the patient.

\section{Author details}

'Department of Nephrology and Dialysis, Tazuke Kofukai Medical Research Institute, Kitano Hospital, 2-4-20 Ohgimachi, Kita-ku, Osaka 530-8480, Japan. ${ }^{2}$ Department of Nephrology, Kansai Electric Power Hospital, 2-1-7 Fukushima, Fukusima-ku, Osaka 553-0003, Japan.

${ }^{3}$ Department of Nephrology, Kyoto University Hospital, 54

Shogoin-Kawahara-cho, Sakyo-ku, Kyoto 606-8507, Japan.

\section{Received: 7 October 2015 Accepted: 13 May 2016}

\section{Published online: 15 August 2016}

\section{References}

1. Sethi S, Fervenza FC, Zhang Y, et al. C3 glomerulonephritis: clinicopathological findings, complement abnormalities, glomerular proteomic profile, treatment, and follow-up. Kidney Int. 2012:82:465-73.

2. Pratt JR, Basheer SA, Sacks SH. Local synthesis of complement component C3 regulates acute renal transplant rejection. Nat Med. 2002:8:582-7.

3. Zuber J, Fakhouri F, Roumenina LT, et al. Use of eculizumab for atypical haemolytic uraemic syndrome and C3 glomerulopathies. Nat Rev Nephrol. 2012;8:643-57.

4. Herlitz LC, Bomback AS, Markowitz GS, et al. Pathology after eculizumab in dense deposit disease and C3 GN. J Am Soc Nephrol. 2012;23:1229-37.

5. Daiana E, Noris M, Remuzzi G. Eculizmab in a patient with dense deposit disease. N Engl J Med. 2012;366:1161-3.

6. Vivarelli M, Pasini A, Emma F. Eculizmab for the treatment of dense-deposit disease. N Engl J Med. 2012:366:1163-5.

7. Radhakrishnan S, Lunn A, Kirschfink M. Eculizmab and refractory membranoproliferative glomerulonephritis. N Engl J Med. 2012:366:1165-6.

8. McCaughan JA, O'Rourke DM, Courtney AE. Recurrent dense deposit disease after renal transplantation: an emerging role for complementary therapies. Am J Transplant. 2012;12:1046-51.

9. Athanasiou Y, Voskarides K, Gale DP, et al. Familial C3 glomerulopathy associated with CFHR5 mutations: clinical characteristics of 91 patients in 16 pedigrees. Clin J Am Soc Nephrol. 2011;6:1436-46.

10. Servais A, Fremeaux-Bacchi V, Lequintrec $M$, et al. Primary glomerulonephritis with isolated $C 3$ deposits: a new entity which shares common genetic risk factors with haemolytic uraemic syndrome. J Med Genet. 2007:44:193-9.

11. Boyer O, Noel LH, Balzamo E, et al. Complement factor $\mathrm{H}$ deficiency and post-transplantation glomerulonephritis with isolated C3 deposits. Am J Kidney Dis. 2008;51:671-7.

12. Vernon $K A$, Gale DP, de Jorge EG, et al. Recurrence of complement factor $H$-related protein 5 nephropathy in a renal transplant. Am J Transplant 2011:11:152-5.

\section{Submit your next manuscript to BioMed Central and we will help you at every step:}

- We accept pre-submission inquiries

- Our selector tool helps you to find the most relevant journal

- We provide round the clock customer support

- Convenient online submission

- Thorough peer review

- Inclusion in PubMed and all major indexing services

- Maximum visibility for your research

Submit your manuscript at www.biomedcentral.com/submit 